\title{
Coronary Anatomy of Commerson's Dolphin (Cephalorhynchus commersonii)
}

\author{
Anatomia Coronaria de la Tonina Overa (Cephalorhynchus commersonii)
}

\author{
Nicolás Picco ${ }^{1}$; Facundo Emmanuel Coton ${ }^{1,2}$; Gregorio Fosser ${ }^{1}$; \\ Edgar Akbhar Guerrero Rojas ${ }^{1,3}$; Guillermo Belerenian ${ }^{4}$ \& Gustavo Abuin ${ }^{1}$
}

PICCO, N.; COTON, F. E.; FOSSER, G.; GUERRERO, R. E. A.; BELERENIAN, G. \& ABUIN, G. Coronary anatomy of commerson's dolphin (Cephalorhynchus commersonii). Int. J. Morphol., 38(1):7-12, 2020.

SUMMARY: The Commerson's dolphin (Cephalorhynchus commersonii) is an odontocete cetacean specie that lies in the waters of the southern hemisphere. With the aim of studying the course and distribution of Cephalorhynchus commersonii's coronary arteries, an exhaustive heart dissection was performed on one specimen. To the extent of our knowledge, and basing upon an extensive bibliographic research on the commersonii species, this is the first reported description of a Commerson's dolphin heart anatomy. Despite the fact that the analysis of a unique specimen does not allow to establish final conclusions, comparisons reveal broad similarities between Cephalorhynchus commersonii's coronary distribution and previous anatomical studies describing the heart of various marine diving mammals and the human fetus circulation. Diving mammals have developed an anastomotic system along evolution, in order to adjust their bodies to diving imposed conditions, and minimize the oxygen demand of the heart muscle. The present work begins with the identification of the patterns and similarities between Commerson's dolphin heart anatomy when compared to other odontecete species, to continue with an exhaustive description of the Commerson's dolphin coronary anatomy.

KEY WORDS: Commerson's dolphin; Cephalorhynchus commersonii; Delphinidae; Coronary arteries; Heart; Anatomy; Sea mammals.

\section{INTRODUCTION}

The Commerson's dolphin (Cephalorhynchus commersonii) is an odontocete cetacean species that inhabits the waters of the southern hemisphere, populating the region between the south of Chile and the Maldive islands (Best, 1988; Bastida \& Rodríguez, 2005). Given the limited number of specimens, this genus among the cetaceans order has been historically understudied from the morphological approach.

Studies performed in other cetacean genus (Truex et al., 1961) have shown broad similarities between the species of this order, specifically respecting the number of coronary arteries, traject, distribution and multiple large and small intercoronary anastomoses in the atrioventricular sulcus and apex (Bisaillon et al., 1988).

Considering that the available morphologic descriptions are based on dissections performed in cetacean species different from commersonii, the objective of the present study was to provide a detailed anatomical description of the coronary system of a Cephalorhynchus commersonii specimen.

The description derives from the thorough dissection work of the coronary tree. In order to illustrate the findings, a series of images is provided along with the corresponding references.

In order to contextualize the results, a retrospective comparison between this study findings and previously published works on the coronary anatomy of humans and other cetaceans species is presented at the end of the article.

\section{MATERIAL AND METHOD}

The heart of a Commerson's dolphin (Cephalorhynchus commersonii) was provided for dissection

\footnotetext{
${ }^{1}$ Heart Laboratory, Institute of Applied Anatomical Sciences Provenzano, School of Medicine, University of Buenos Aires, Buenos Aires City, Argentina

${ }^{2}$ Maternity Hospital of San Isidro, Buenos Aires Province, Argentina.

${ }^{3}$ Institute of Health Sciences H. A. Barceló, Buenos Aires, Argentina.

${ }^{4}$ Veterinary Clinical Cardiology and Cardiovascular Surgery of Buenos Aires, University of Buenos Aires, Buenos Aires City, Argentina.
} 
by one of the authors (G. Belereniam). The heart weighed $149 \mathrm{~g}$ when eviscerated. The reported organ belonged to an adult male specimen; measurements of the specimen were:total length, $137 \mathrm{~cm}$; weight, $38.4 \mathrm{~kg}$ at the moment of death. (The cause of death was not determined in this study; however, no signs of ischemia, valvular or muscular malformations were found in the heart of the specimen).

Following the evisceration process, the heart was isolated and fixed in $10 \%$ formaldehyde during 14 days. Once the fixation process was completed, the organ was measured and the dissection of the coronary tree was performed. Naked eye dissection was used as a first approach to address the rough features of the cardiovascular anatomy; x10 microscopy and Dumont tweezers were used to dissect the anatomical details.

The complete dissection work was carried out over 40 days. The pictures of the anatomical details were taken with a Nikon D7000 digital camera, equipped with a Micro NIKKOR $60 \mathrm{~mm}$ lenses and then edited using Photoshop CS4 software.

The dissected heart, as well as the tools and materials employed for its dissection, are labeled and preserved in the facilities of the Heart Laboratory from the "Institute of Applied Anatomical Sciences Provenzano", Medical School of Buenos Aires, Argentine.

\section{RESULTS}

Gross Anatomy: It is possible to distinguish a ventral and a diaphragmatic surface; two borders coincident with the right and left cardiac margins; a base and an apex.

The heart is divided into four chambers: two atria, left and right, separated from their respective ventricles by the atrio-ventricular sulci, which remains partially covered by the external surface of the auricles.

The muscle that belongs to the ventricular surface can be distinguished by its characteristic smooth and homogeneous texture; conversely, the external configuration of the atrial cavities present an irregular and extensive array of pectinate muscles.

From a cephalic view, two large vessels can be distinguished. The pulmonary artery, that arises from the right ventricle, describes a traject from right to left, ventral to dorsal and in a cephalic direction. Dorsal to this last one the aorta arises from the left ventricle, with a left to right, dorsal to ventral traject.

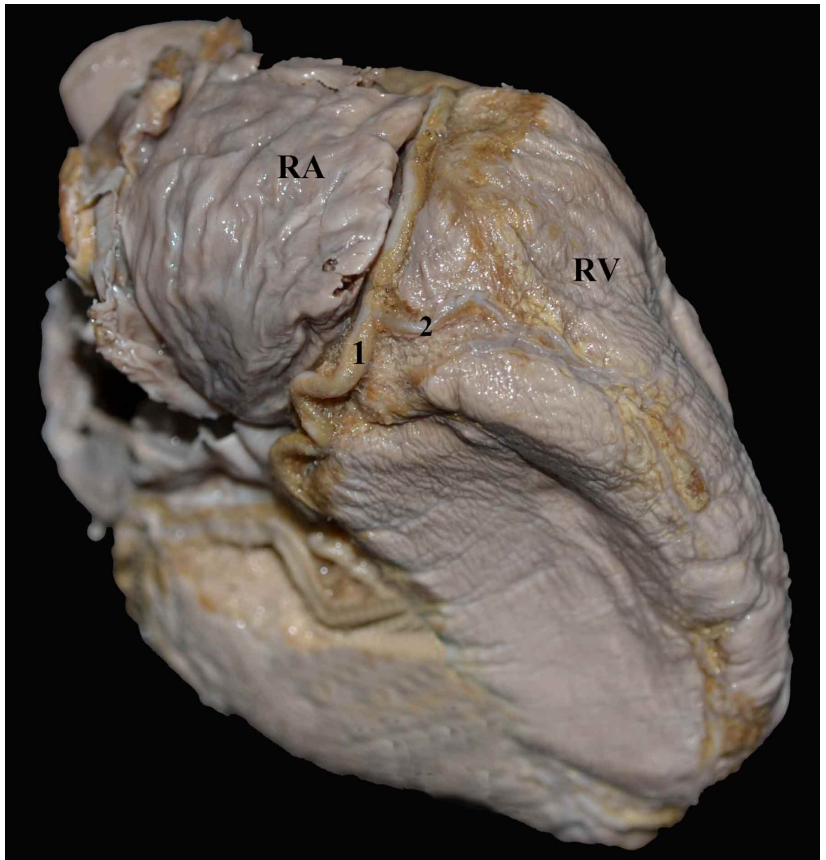

Fig. 1. View from the right side of the heart. The right coronary artery (1) can be appreciated supplying the right marginal branch (2) on the right edge of the heart. RA: right atrium, RV: right ventricle.

Right coronary artery: The right coronary artery arises from the right ventral aortic sinus, located $8 \mathrm{~mm}$ above the insertion of the aortic valve.

It describes a dorsal to ventral traject of $3 \mathrm{~mm}$ along the external suface of the heart until it reaches the right atrioventricular sulcus, where it supplies two main branches that irrigate the margo acutus.

The right coronary artery continues its downward course through the right atrioventricular sulcus, towards the diaphragmatic aspect of the heart where it divides into two primary branches: the posterior descending artery and the atrioventricular branch (retroventricular artery) (Fig. 1).

The posterior descending artery can be the terminal branch of the right coronary artery or the terminal branch of the circumflex artery. In particular cases, it has been documented that there can co-exist a right and a left posterior descending arteries, originated from the right coronary artery and the circumflex artery respectively. In the case concerning this study, the dominant artery was the left one (circumflex artery), as the first septal artery originates from the right posterior descending artery.

For the purposes of this paper the right coronary artery is analyzed in three segments: 
A) Proximal segment: it extends from the artery's origin up to its entry in the Right Atrioventricular Sulcus.

B) Middle segment: it extends along the acute border of the heart. As the artery proceeds its traject, five ventricular branches are supplied, from which the right marginal artery is the most relevant one, with a caliber of $1 \mathrm{~mm}$ at its arising point.

The total length of the right marginal artery is 53 $\mathrm{mm}$; it culminates its course by dividing in several small branches that supply the free wall of the right ventricle.

The right marginal artery stands as a reference point to delimitate the middle from the distal segment of the right coronary artery.

C) Distal segment: while continuing its course, the right coronary artery supplies a number of small branches to the diaphragmatic surface of both right chambers. Eigth mm before reaching the posterior interventricular sulcus, the artery divides in two branches: the right retroventricular branch (atrioventricular branch) and the posterior interventricular artery (right posterior descending artery).

The posterior interventricular artery immediately directs its course towards the cardiac apex, where it finishes in small branches that widely distribute along the region, irrigating the diaphragmatic surface of both ventricles and the ventricular septum, and establiblishing an anastomosis with the left posterior descending artery.

Left coronary artery: The left coronary artery arises from the left aortic sinus, $10 \mathrm{~mm}$ above the insertion of the left aortic valve. After a traject of $6 \mathrm{~mm}$ from the site of origin, the artery divides in three main vessels: the anterior interventricular artery (anterior descending artery), the intermediate branch and the circumflex artery.

Anterior interventricular artery: With a caliber of $4 \mathrm{~mm}$ at its arising point, this vessel pursues a course of $84 \mathrm{~mm}$ length along the anterior interventricular sulcus supplying branches to both ventricles and interventricular septum (Fig. 2) until it reaches the cardiac apex.

It is important to highlight that in the apex region of the commersonii's heart, the anterior interventricular artery anastomoses with the posterior descending artery, branch of the left circumflex artery (Fig. 3); collateral branches emerging from this anastomotic point additionally anastomose with the left marginal artery (branch of the circumflex artery), and with the right marginal artery (branch of the right coronary artery).

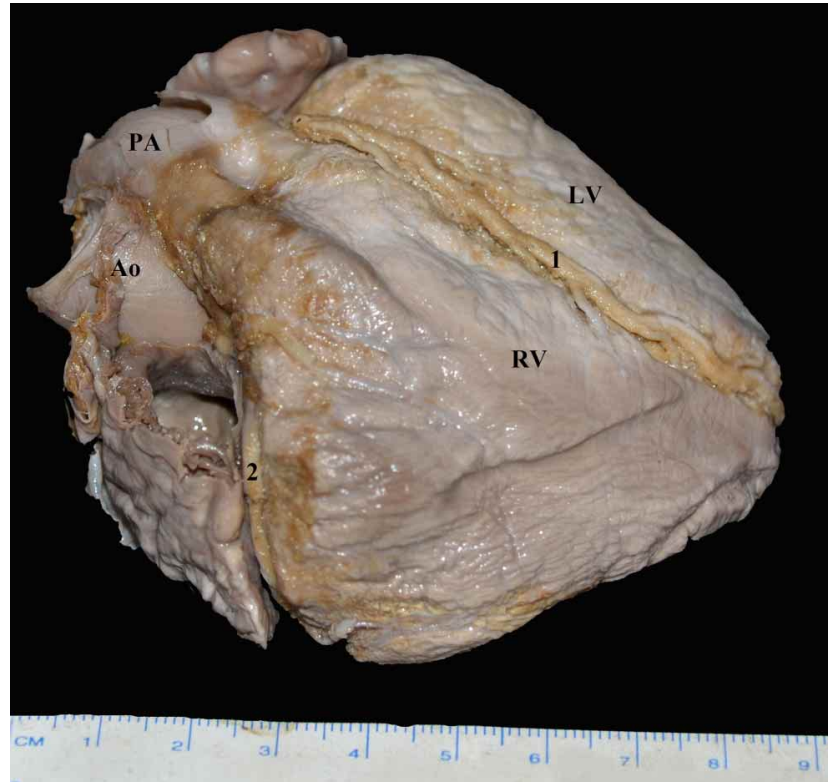

Fig. 2. Right superior oblique view. The anterior interventricular artery (1) runs between the right ventricle (RV) and left ventricle (LV). The right coronary artery (2) can be observed between the right atrium and the right ventricle. The pulmonary artery (PA) can be seen arising from the right ventricle; in a posterior situation respecting the PA the Aorta (Ao) can be recognized.

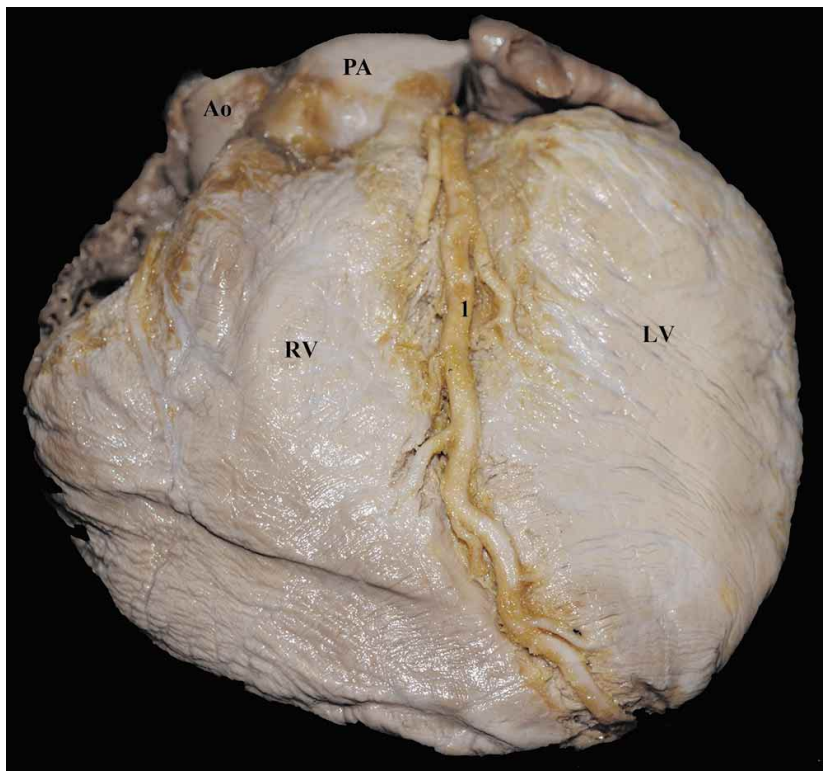

Fig. 3. Ventral surface of the heart. The anterior interventricular artery (1) runs between the right ventricle (RV) and the left ventricle (LV). Above, the pulmonary artery (PA) can be observed leaving the right ventricle. Partially covered by the trunk of PA, the Aorta (Ao) emerges from the left ventricle (LV).

Circumflex artery: The circumflex artery originates from the trunk of the left coronary artery; its arising point remains hidden to the naked eye by the trunk of the pulmonary artery; after a short traject, the circumflex artery enters the left 
atrioventricular sulcus (Fig. 4). It pursues its course towards the diaphragmatic surface of the heart, providing small branches along the way that supply the left chambers of the heart, the distribution of these small branches is similar to that found in humans (Fig. 5). Once the vessel reaches the posterior interventricular sulcus it changes its course in 90 degrees and is hereinafter referred to as posterior interventricular artery (posterior left descendent).

One of the main branches of the circumflex artery, during its mentioned traject along the atrioventricular sulcus, is the left marginal artery. A number of intracoronary anastomoses were found along the free wall of the left ventricle between the left marginal artery and the anterior descending artery.

Posterior interventricular artery: In the studied commersonii specimen, two arteries run along the posterior interventricular sulcus: the right posterior descending artery (branch of the right coronary artery) and the left posterior descending artery (branch of the circumflex artery). Both vessels establish an anastomosis in the posterior interventricular sulcus, at approximately $20 \mathrm{~mm}$ from the atrioventricular sulcus.

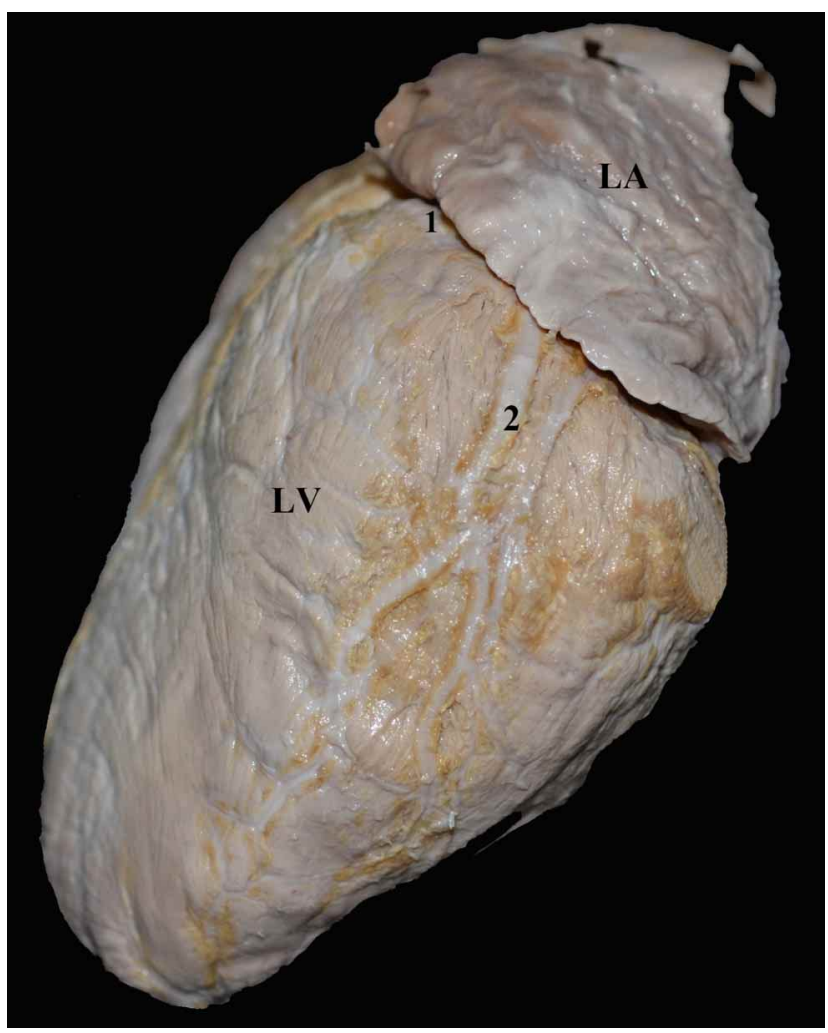

Fig. 4. Left view. The circumflex artery (1) can be seen traveling the left atrioventricular groove towards the posterior wall of the heart. This artery gives off the left marginal branch (2), which runs along the acute border of the heart towards the apex.
Although, it is important to highlight that the left posterior descending artery is the only one reaching the cardiac apex region (Fig. 5), where it anastomoses with the anterior interventricular artery (anterior descending) (Fig. 6); while the right posterior descending artery ends in small branches irrigating the diaphragmatic surface of both ventricles, and anastomosing, as mentioned, with the left posterior descending artery.

Intercoronary anastomoses: In Commerson's dolphin intercoronary anastomoses seem to play a major role in vascularization, after dissection they are easily noticed by the observer's eye.

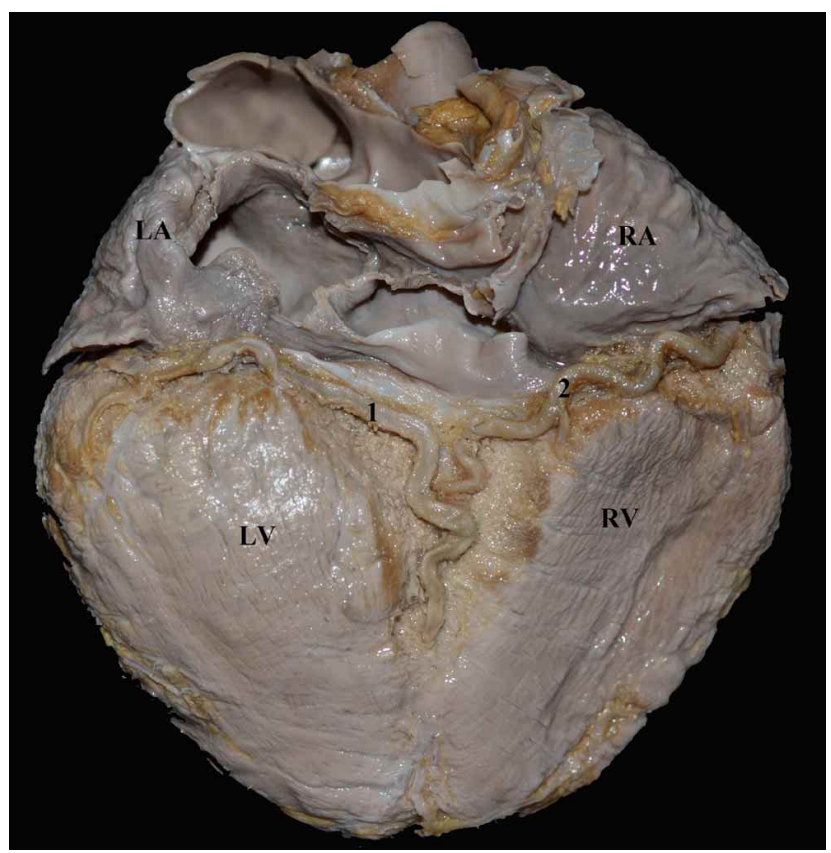

Fig. 5. Diaphragmatic surface of the heart. The circumflex artery (1) follows its course between the left atrium (LA) and left ventricle (LV). The right coronary artery (2) is recognized between the right atrium (RA) and right ventricle (RV). Both arteries cross and then take a descending pathway forming the posterior interventricular artery, which directs towards the apex.

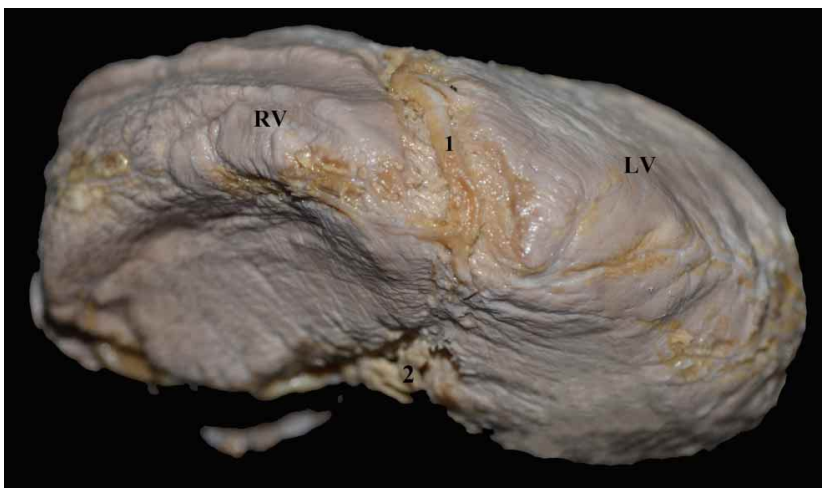

Fig. 6. Apex of the heart. Anastomosis between the anterior interventricular artery (1) and the posterior interventricular artery (2). 
The most significant anastomotic network found in this specimen is located in the apex of the heart. A thorough dissection of the apex allows appreciating this network arising from small branches provided by the anterior interventricular artery, the posterior interventricular artery and left and right marginal branches (Fig. 7).

Other smaller anastomotic networks take place between the conus branches in the surface of the right ventricular outflow tract, and between the obtuse marginal branch and the anterior descending artery in the acute border of the heart.

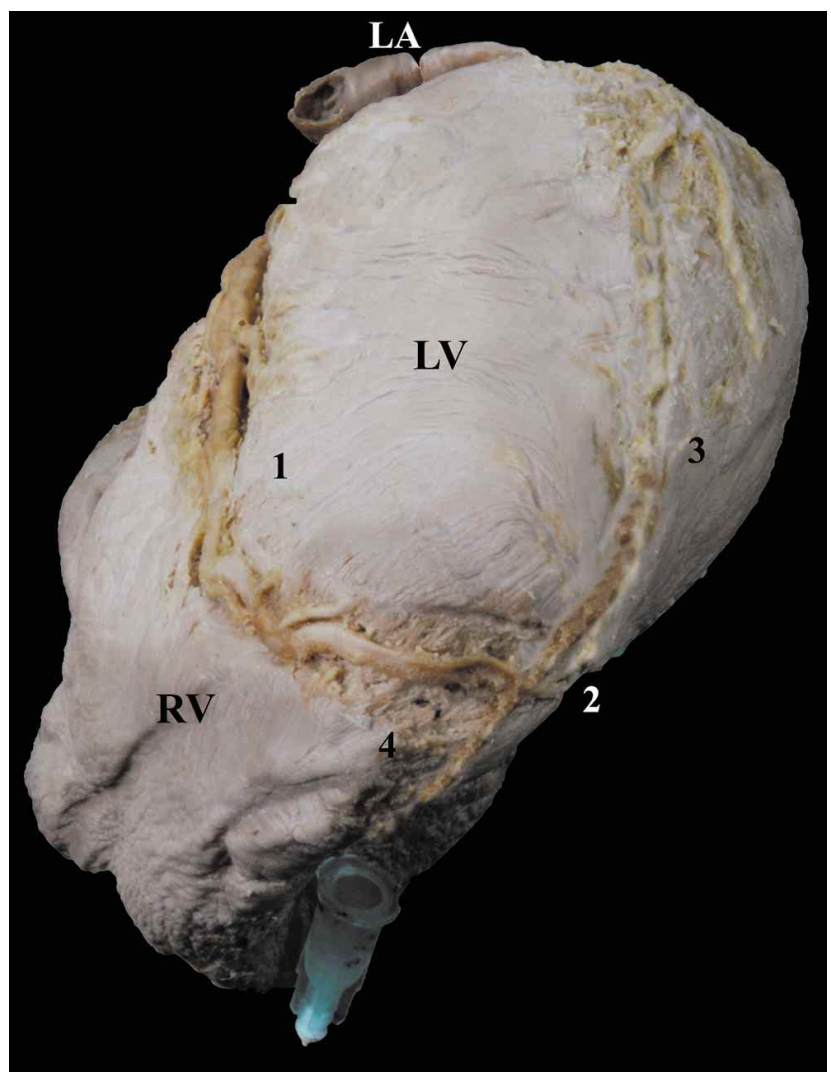

Fig. 7. Apex of the heart. 2nd stage of the dissection process. An anastomotic network takes place in the apex between the anterior interventricular artery (1), the posterior interventricular artery (2) and small branches originated in the left marginal artery (3) and right marginal artery (4).

\section{DISCUSSION}

Studies by Truex et al. describe hearts of different species of cetaceans such as Sperm Whale (Physetermacrocephalus), Gray Whale (Eschrichtiusrobustus) and Sei Whale (Balaenoptera borealis). In each and every heart, macroscopic intercoronary anastomoses were identified in the absence of obstruction. In comparison, adult human's coronary collateral circulation develops only in association with progressive obstructive diseases, implying severe narrowing (at least 70-90\% stenosis) or complete obstruction in one of the coronary vessels, that will participate in the developing anastomotic circuit (Levin, 1974). We can suspect that the anastomotic network in diving mammals aims to maintain an adequate myocardial perfusion, providing a greater blood flow to it, along with others described physiological adaptations to alleviate hypoxia conditions under water; for example, cetaceans have high levels of hemoglobin, hematocrit and neuroglobin expression levels in their brains (Tian et al., 2016).

Heart rate in fetal Wedell Seals reported that mammalian fetuses present throughout their development gradual physiological changes seeking to adapt to his mother's response during immersion, and develop an appropriate diving bradycardia response, however with slower on and offset (Zapol, 1987).

The human fetus has objectionable coronary anastomoses between left and right arteries, a fact that had been pointed out by investigations carried out in the XX century (Spalteholz, 1924).

However, during postnatal life, humans largely lost the functionality of these anastomoses, keeping the possibility of restitution.

In the offspring of marine mammals it is assumed this anastomoses remain permeable and even may develop further as the animal develops increasingly deep and prolonged dives in virtue of the chronic diving hypoxia.

It is possible to assume that the extensive collateral circulation present in cetaceans responds to a series of adaptive mechanism seeking to achieve a higher diving performance by adjusting the anatomy of the animal and physiology to adapt easily to the chronic decreased partial pressure of oxygen during diving.

To the extent of our knowledge, this is the very first dissection of the coronary vascular system of these specimens.

PICCO, N.; COTON, F. E.; FOSSER, G.; GUERRERO, R. E. A.; BELERENIAN, G. \& ABUIN, G. Anatomia coronaria de la tonina overa (Cephalorhynchus commersonii). Int. J. Morphol., 38(1):7-12, 2020.

RESUMEN: La tonina overa (Cephalorhynchus commersonii) es una especie de cetáceo odontoceto que se encuentra en las aguas del hemisferio sur. Con el objetivo de estudiar el curso y la distribución de las arterias coronarias de Cephalorhynchus commersonii, se realizó una disección exhaustiva del corazón de 
un ejemplar. Hasta donde sabemos, y basándonos en una extensa investigación bibliográfica sobre la especie, esta es la primera descripción informada de la anatomía de un corazón de este ejemplar. A pesar de que el análisis de una sola muestra no permite establecer conclusiones finales, las comparaciones revelan amplias similitudes entre la distribución coronaria de Cephalorhynchus commersonii, los estudios anatómicos previos que describen el corazón de varios mamíferos marinos buceadores, y la circulación del feto humano. Los mamíferos buceadores han desarrollado un sistema anastomótico a lo largo de la evolución para ajustar sus cuerpos a las condiciones impuestas por el buceo y minimizar la demanda de oxígeno del músculo cardíaco. El presente trabajo comienza con la identificación de los patrones y similitudes entre la anatomía del corazón de tonina overa en comparación con otras especies odontecetas, continuando con una descripción exhaustiva de la anatomía coronaria.

PALABRAS ClAVE: Delfín de Commerson; Cephalorhynchus commersonii; Delphinidae; Arterias coronarias; Corazón; Anatomía; Mamíferos marinos.

\section{REFERENCES}

Bastida, R. \& Rodríguez, D. Marine Mammals of Patagonia and Antarctica. Buenos Aires, Vázquez Mazzini, 2005.

Best, P. B. The external appearance of Heaviside's dolphin, Cephalorhynchus heavisidii (Gray, 1828). Rep. Int. Whal. Commn. (Special Issue 9):279-99, 1988.

Bisaillon, A.; Martineau, D.; St-Pierre, M. A. \& Béland, P. Arterial and venous vasculature of the heart of the beluga whale (Delphinapterus leucas). J. Morphol., 195(3):305-12, 1988.

Levin, D. C. Pathways and functional significance of the coronary collateral circulation. Circulation, 50(4):831-7, 1974.

Spalteholz, W. Die Arterien der Herzwand. Anatomische Untersuchungen an Menschen und Tieren. Leipzig, S. Hirzel, 1924.

Tian, R.; Wang, Z.; Niu, X.; Zhou, K.; Xu, S. \& Yang, G. Evolutionary genetics of hypoxia tolerance in cetaceans during diving. Genome Biol. Evol., 8(3):827-39, 2016.

Truex, R. C.; Nolan, F. G.; Truex, R. C. Jr.; Schneider, H. P. \& Perlmutter, H. I. Anatomy and pathology of the whale heart with special reference to the coronary circulation. Anat. Rec., 141:325-53, 1961.

Zapol, W. M. Diving adaptations of the Weddell seal. Sci. Am., 256(6):100$5,1987$.
Corresponding author:

Nicolás Picco

Heart Laboratory

Institute of Applied Anatomical Sciences Provenzano

School of Medicine

University of Buenos Aires

Buenos Aires City

Riobamba 651 “5”B. C.A.B.A

ARGENTINA

Email:npicco@fmed.uba.ar

Received:10-04-2019

Accepted:21-08-2019 